\title{
Entrevista a Ángela Yasmith Cerón Lasprilla ${ }^{1}$
}

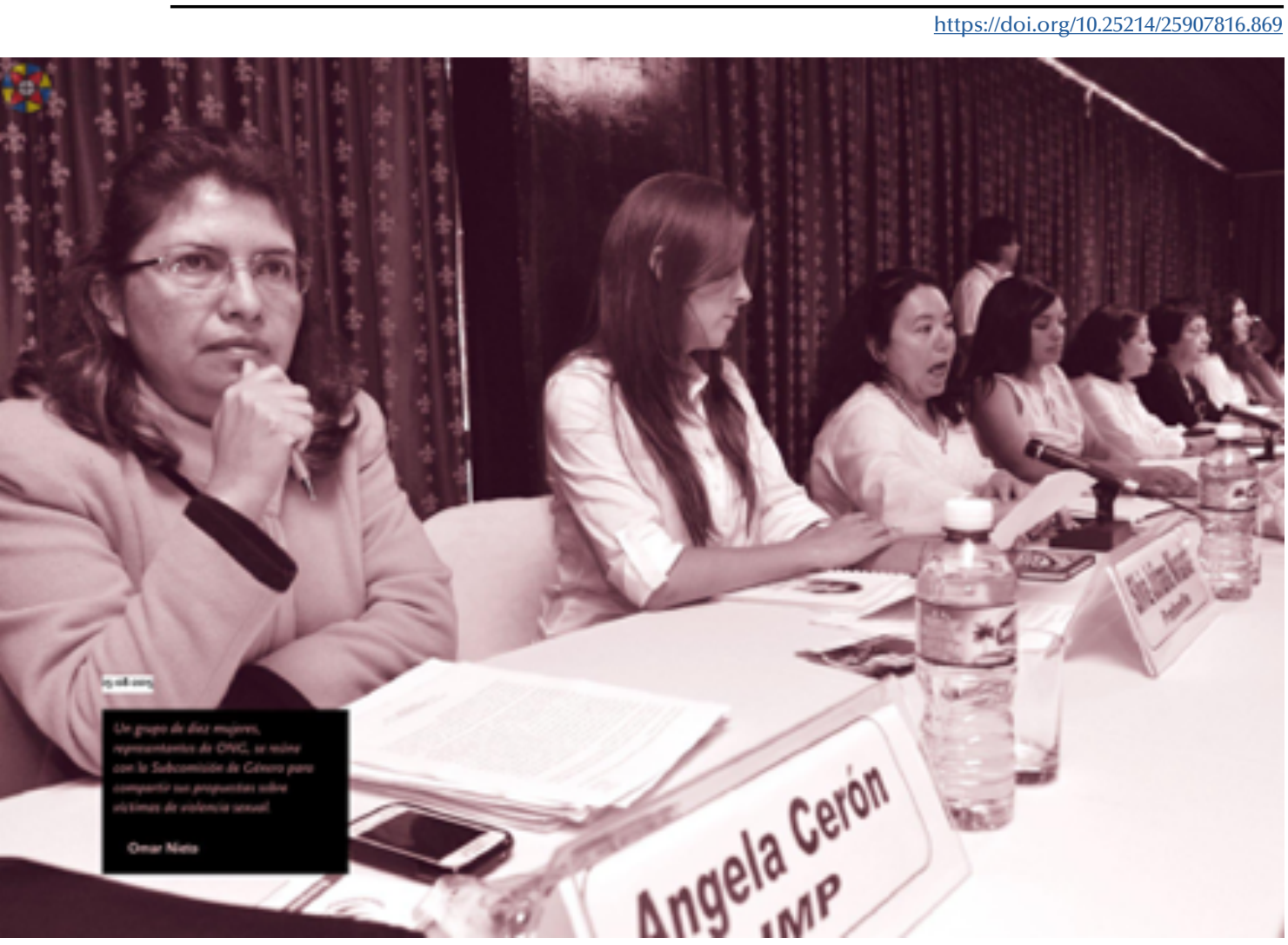

Ángela Cerón Lasprilla y otras mujeres representantes de organizaciones reunidas con la Subcomisión de Género de los Diálogos de Paz de La Habana. Fotografía: Omar Nieto (2015).

Muchas personas desconocen que una terapeuta ocupacional ha hecho parte de los diálogos de paz que se han dado en Colombia en las últimas décadas. Desde el fallido proceso de negociación del Caguán, a finales de los noventa, hasta los recientes avances con el Ejército de Liberación Nacional - ELN, Ángela Cerón Lasprilla ha sido testigo y protagonista de estas aproximaciones a la solución negociada al conflicto armado colombiano, como parte de su compromiso con el acompañamiento y el liderazgo de las mujeres, que asumió desde muy temprano en su carrera profesional. Actualmente, Ángela es directora de la Alianza Iniciativa de Mujeres Colombianas por la Paz - IMP.

${ }^{1}$ Terapeuta Ocupacional. Especialista en Mujer, Género y Desarrollo. Directora, Alianza Iniciativa de Mujeres Colombianas por la Paz - IMP. Bogotá, Colombia. direccion@mujeresporlapaz.org 
La editora de la Revista Ocupación Humana la entrevistó el 11 de marzo de 2020 en su oficina en Bogotá. Esta conversación giró alrededor de su recorrido por estos procesos, que es, de alguna manera, parte de la historia de las negociaciones de paz en el país. También contó algunas de sus reflexiones sobre la Terapia Ocupacional, a partir de su experiencia.

En este número, dedicado al tema de la participación de la profesión en la construcción de paz en Colombia, reconocer el trabajo de Ángela es ineludible e inspirador. A continuación, se presenta la edición de algunos apartes de esa entrevista.

\section{Antecedentes: el acercamiento desde la Terapia Ocupacional a los asuntos de género y al activismo político y social}

Hice la pasantía ${ }^{2}$ de un acuerdo que firmó la Central Unitaria de Trabajadores - CUT con el Departamento de la Ocupación Humana de la Universidad Nacional para hacer orientación ocupacional con mujeres líderes sindicales que habían perdido sus puestos de trabajo por toda la reestructuración que había implementado el gobierno de César Gaviria3. Muchas mujeres habían salido de sus puestos de trabajo con recursos, pero sin un plan de vida; esa era la tarea que teníamos que hacer.

Más adelante se constituye un espacio que se llama la Casa de la Mujer Trabajadora - CUT y empezamos a trabajar con mujeres de escasos recursos para orientarlas en oficios no tradicionales. Ahí sale la oportunidad de estudiar en la Universidad Nacional el posgrado de Mujer, Género y Desarrollo; ese programa me dio luces de cómo podríamos, desde las mujeres, incidir en la formación de los liderazgos de ellas.

A mí ese tipo de acciones me gustaban más que la orientación de Terapia Ocupacional de sentarme con la persona y decirle: miremos a ver sus habilidades. El liderazgo me parecía que transformaba quizás más los escenarios, así que me dediqué más a la Escuela de Liderazgo, a identificar a las líderes, centrarnos en su formación, y así, poco a poco, me fui quedando más en ese ámbito.

\section{La primera aproximación a los diálogos de paz}

Hacia el año 2000, el país contaba con un proceso de negociación en San Vicente del Caguán entre el Gobierno, en cabeza de Andrés Pastrana, y las FARC-EP4. Noso-

\footnotetext{
${ }^{2}$ Como opción de grado para optar al título de terapeuta ocupacional de la Universidad Nacional de Colombia, que obtuvo en 1996. Su trabajo se denominó Aproximación del programa Reorganización del Desempeño Ocupacional de Mujeres Trabajadoras a una perspectiva de género y fue dirigido por la profesora Martha Torres de Tovar. El texto está disponible en la biblioteca central de la Universidad Nacional de Colombia, en Bogotá.

${ }^{3}$ César Gaviria Trujillo fue presidente de Colombia entre 1990 y 1994. Durante su Gobierno se implementaron una serie de reformas de corte neoliberal que incluyeron la privatización, eliminación, fusión y reestructuración de entidades del Estado (Martínez, 2015).

${ }^{4}$ Este proceso de negociación entre el Gobierno Nacional, bajo la presidencia de Andrés Pastrana Arango, y las Fuerzas Armadas Revolucionarias de Colombia - Ejército del Pueblo - FARC-EP inició en 1998 y se dio por terminado en febrero del 2002, sin que se llegara a un acuerdo (Ríos y Fuentes, 2014).
} 
tras, y digo nosotras como Departamento de la Mujer de la CUT, nos preguntamos si era importante estar en ese espacio. Fue una reflexión interna, porque parte del movimiento de mujeres no estaba de acuerdo en ir a hablar con los guerreros, la otra parte decía sí. La verdad es que fue una audiencia especial, que tanto el Gobierno como las FARC-EP aceptaron, y nosotras como trabajadoras dijimos: ;tenemos que ir!

Yo estaba acompañando, ahí ni hablé, pero fuimos con muchas mujeres ${ }^{\mathbf{6}}$ de municipios cercanos a San Vicente y logramos medir un poco el escenario de la negociación, en qué condiciones estaba. Era como un espacio de ver a los guerreros de cerca en una situación que no es fácil para las mujeres, pero que sí nos preguntábamos: bueno, ¿cómo es una negociación?¿dónde pueden estar las mujeres?

En ese momento, una compañera del Sindicato de Trabajadores Estatales de Suecia - ST, Irene Nilsso, nos dice: ¿cómo así que vienen a Europa a hacer una visita la delegación de las FARC-EP y la delegación del Gobierno, y aquí no están las mujeres? Ella plantea entonces que una delegación de mujeres fuéramos a Suecia a conversar sobre lo que estaba pasando en Colombia y abrir un escenario diferente, plantear nuevas cosas. El Departamento de la Mujer de la CUT, junto con otras organizaciones de mujeres, tomamos la decisión de viajar. Viajamos el 10 de septiembre de 2001, pero cuando llegamos a Suecia ya las torres gemelas no existían y el mundo había cambiado... fue muy fuerte... era enfrentarnos a una situación nueva frente al conflicto que vivía Colombia, las FARC-EP fue catalogado como grupo armado terrorista. ¿Qué iba a pasar con la gente? ¿Cuál iba a ser el rumbo de la negociación? Fue una situación de enfrentarnos a una realidad fuera del país, en un contexto diferente, pero también de mirar cómo podríamos actuar en ese momento.

\section{La organización social como base para participar en la construcción de paz}

En Suecia tuvimos unas etapas de capacitación con una líder que impulsó la Resolución 1325 del Consejo de Seguridad de las Naciones Unidas ${ }^{7}$, una senadora sueca. Ella nos insistía mucho en la participación de las mujeres en el proceso de paz y que era necesario hacer visibles a las mujeres porque el conflicto se vivía de diferente manera. Era más arraigado el tema de atentar contra las mujeres como un objetivo y dañarlas, sobre todo creyendo que eran las esposas, las hijas de la contraparte y así era más fácil atacar al enemigo. Eso no lo entendíamos muy bien, pero sabíamos que esa

\footnotetext{
${ }^{5}$ Ángela aclara, con posterioridad a esta entrevista: "me refiero a los guerreros porque en la audiencia los actores principales eran la FARC-EP y los representantes del Estado como monopolio de la fuerza".

${ }^{6}$ En otro momento de la entrevista, que no se transcribe por completo aquí, Ángela relata que participaron en ese encuentro mujeres de 84 u 85 organizaciones.

${ }^{7}$ Esta Resolución, aprobada por el Consejo de Seguridad de Naciones Unidas el 31 de octubre del 2000, "reconoce la importancia de la participación de las mujeres, así como de la inclusión de la perspectiva de género en las negociaciones de paz, la planificación humanitaria, las operaciones de mantenimiento de la paz, la consolidación de la paz en las situaciones posteriores a un conflicto y la gobernanza" (ONU Mujeres, s.f.). El texto completo de la Resolución está disponible en: https://undocs.org/es/S/RES/1325\%20\%282000\%29
} 
Resolución era muy importante, así que cuando regresamos la estudiamos muy bien y empezamos a trabajar. Suecia quedó muy impactada con nuestro trabajo, así que nos dijo que nos iba a seguir apoyando dos años más con una experta feminista que se Ilama Caroline Moser. Ella nos dijo: hay que construir una agenda en común. Ahí empieza la Alianza Iniciativa de Mujeres Colombianas por la Paz - IMP a trabajar una agenda en común y así llegamos más al tema de paz, a fortalecerlos desde la Resolución 1325 y el apoyo de Suecia para tener impacto en las organizaciones de mujeres.

Era como en los años 2001, 2002, 2003; trabajamos desde la identidad de los "sectores": indígena, campesino, sindical, académico, feminista, afrodescendiente, juventud y otros; luego cambiamos a la lógica de trabajo desde lo municipal-región, donde se interrelacionan los sectores. Esa fue una decisión bien importante para la Alianza IMP, porque nos permitió, primero, ubicarnos en los territorios, decir: estamos en tal municipio porque hay una líder indígena o campesina que va a estar jalonando el proceso de la Alianza... eso nos dio estructura, realmente nos dio una base fuerte de presencia y de trabajo social, ser interlocutoras validas... un poco a semejanza de los partidos políticos y la misma estructura de un sindicato, pero también reconociendo que las correlaciones de fuerzas van cambiando y, por lo tanto, nuestra presencia en los municipios (que se liga a la participación en el diseño de los planes de desarrollo, la presencia de nuestras delegadas en los espacios de decisión municipal y, algunas veces, en cargos de elección popular) es consecuente con la lectura de los contextos, siempre en pro de los derechos de las mujeres desde el enfoque de género y el derecho a la paz.

\section{El proceso con las Autodefensas Unidas de Colombia - AUC}

Viene el proceso de negociación con los paramilitares ${ }^{8}$ y la Alianza IMP toma la decisión, en aras de la Resolución 1325, de decir: este es un proceso de negociación, los paramilitares son un grupo armado y, por lo tanto, tenemos que estar ahí. En ese momento era el vicepresidente Francisco Santos y estaba Luis Carlos Restrepo ${ }^{9}$, en algún momento nos preguntan si queremos ir a Santa Fe de Ralito, dijimos: pues sí, no le vemos problema, van a iniciar la negociación, está una ley de por medio, no le vemos problema alguno a ir.

Llegamos allá, éramos diez, varias eran víctimas de los paramilitares. El objetivo era decirles: señores, nosotras vamos a apoyar a las víctimas, este tiene que ser un proceso de negociación, la voz de las mujeres va a hacer presencia acá. La Resolución 1325 era como nuestro mandato y conformamos una comisión de observación. Después nos reunimos con la MAPP-OEA ${ }^{10}$ y Sergio Caramagna ${ }^{11}$ nos decía: es muy importante que

\footnotetext{
${ }^{8}$ El proceso de conversaciones entre el Gobierno del entonces presidente Alvaro Uribe Vélez y las Autodefensas Unidas de Colombia - AUC se desarrolló entre finales del año 2002 y el año 2005 , cuando se firma, producto de las mismas, la Ley de Justicia y Paz (Ley 975 del 2005) (Centro Nacional de Memoria Histórica, 2018).

${ }^{9}$ Francisco Santos ocupaba la Vicepresidencia de la República y Luis Carlos Restrepo era Alto Comisionado de Paz, responsable del proceso por parte del Gobierno Nacional (Vacas, 2014).

${ }^{10}$ Misión de Apoyo al Proceso de Paz en Colombia de la Organización de los Estados Americanos. "Organismo internacional que desde 2004, por solicitud del Estado colombiano, ha monitoreado y acompañado de manera ininterrumpida las políticas de paz en el país" (OEA-MAPP, s.f.).

11 Jefe de la Misión de Apoyo al Proceso de Paz en Colombia de la Organización de los Estados Americanos, acompañó el proceso de desmovilización paramilitar entre 2004 y 2008 (OEA-MAPP, 2019).
} 
estén acá; pues claro, era legitimar el proceso y nosotras lo entendíamos plenamente. Eso significó que el movimiento de mujeres y la CUT nos cuestionara y en algunos casos nos sacaran de varios escenarios. Para muchos no éramos garantes. Pero dijimos, ya nos toca salir de esto porque qué podemos hacer.

Nosotras empezamos a asumir la decisión de acompañar a las víctimas del conflicto armado... bueno, lo primero fue apropiarnos del proceso de construcción de la ley. Pero no éramos expertas en derecho, entonces tampoco era que fuéramos a transformar la propuesta de Ley en el Congreso... así que buscamos apoyo con otras organizaciones, la Red Nacional de Mujeres, y con ellas incidimos. Es decir, donde veíamos que podíamos meter el tema de los derechos de las mujeres, el tema de violencia sexual y garantías para ellas, lo incluíamos, porque desde el comienzo habíamos entendido que este tipo de violencia en el conflicto era gravísimo. Lo que está en esa Ley ${ }^{12}$ sobre derechos de las mujeres, todo eso lo incluimos. Cuando sale la Ley de Justicia y Paz, igual nosotras la demandamos como lo hizo todo el movimiento de derechos humanos y de mujeres; finalmente la Corte Constitucional la ajusta en pro de los derechos de las víctimas y dice: la Ley va así.

\section{La participación en Justicia y Paz en representación de mujeres víctimas}

La embajada de Suecia dijo: bueno, vamos a apoyarlas porque ustedes representan a las víctimas... empezamos a averiguar con la compañeras en los municipios si había víctimas y iclaro! encontramos cerca de 460, víctimas de paramilitares, de guerrillas y de militares, y empezamos a documentar.

La Justicia Transicional en Colombia inicio con la Ley 975 de 2005, en este contexto la Fiscalía General de la Nación creó la Unidad de Justicia y Paz, la Procuraduría dispuso una Unidad, la Defensoría del Pueblo también, pero esa Unidad de Justicia y Paz en la Defensoría al inicio solamente atendía a los paramilitares, no a las víctimas. Cuando nombraron a Luis González ${ }^{13}$ en la Unidad de Justicia y Paz de la Fiscalía nosotras fuimos y le mostramos los casos, pero él nos dijo que eso no tenía ni modo, ni tiempo, ni lugar. Nosotras no teníamos ni idea de la documentación... creo que el primer caso que documenté fue como identificando las habilidades de la señora-víctima, preguntándole qué era lo que hacía antes de vivir el hecho victimizante, antes del conflicto, como una entrevista de terapeuta ocupacional.

Así que ahí logramos contratar dos abogadas y ya con ellas más o menos nos acercamos al tema jurídico. Ya hacia el año 2008 o 2009 empiezan muchas audiencias a la vez y no teníamos todas las abogadas para hacer presencia en ellas. En

\footnotetext{
${ }^{12}$ Se refiere a la Ley de Justicia y Paz (Ley 975 de 2005), con la cual finalizó la negociación con el grupo paramilitar. Según refiere Ángela en la entrevista, su trámite en el Congreso duró entre ocho y diez meses, y dos legislaturas.

${ }^{13}$ Director de la Unidad de Justicia y Paz de la Fiscalía General de la Nación desde su creación, en 2005, hasta el año 2011 (La Silla Vacía, 2017).
} 
esa época tuvimos muchos problemas en la Alianza-IMP. Entonces, en enero de 2009, se crea la personería jurídica de la Alianza Iniciativa de Mujeres Colombianas por la Paz - IMP y asumo la dirección. Claro, la asumo con muchas dificultades, porque yo me estaba consolidando hasta ahora y ya no tenía el respaldo pleno de la CUT, aunque seguía teniendo el apoyo de la Embajada de Suecia y del Sindicato de la ST.

Ahí viene todo el reto del escenario jurídico. Justicia y Paz se desarrolló en Barranquilla, con una unidad móvil satelital en Bucaramanga, Bogotá y Medellín. Las audiencias eran allá y se contaba con la participación de 60, 80 o 100 víctimas al mismo tiempo, y yo solamente tenía dos abogadas... así que por recomendación de un abogado asumí la representación jurídica de todos los casos y lo que hacía era delegar a las abogadas; donde no se podía, pues delegaba a la encargada política municipal, departamental o regional de la Alianza IMP. Era acompañar a las víctimas, no solo fueron mujeres, también hombres ${ }^{14}$, que estaban en esos procesos presentando sus casos, era versión libre. Allí el paramilitar empezaba a contar su historia, lo que había pasado, hasta que llegaba un momento en el que las víctimas podían intervenir y preguntar; ese era el momento más duro de nosotras para acompañarlas. En Justicia y Paz es un logro que realmente ni siquiera los abogados y abogadas de gran trayectoria saben cómo lo logramos, pues porque todas, absolutamente todas mis compañeras en los territorios ganaron legitimidad con las víctimas y en el estrado judicial, siempre tuvimos un trato igual por parte del juez y de la Fiscalía, nos sentamos al mismo nivel que los abogados de la defensa-victimario y hacíamos preguntas para develar la verdad de las víctimas que representamos.

A veces digo, ¿yo en qué me metí? y digo, nada, nos tocaba. $Y$ es que los casos que nos encontrábamos son emblemáticos: Hernán Giraldo, el Taladro, en la Sierra Nevada de Santa Marta; Marcos Tulio Pérez Guzmán, alias el Oso, en Libertad ${ }^{15}$, Sucre, y el caso de la rectora que entregaba a los niños y niñas para ser víctimas de violencia sexual con su esposo el concejal. Luis Gonzáles me decía: ¿esos casos usted los busca o ellos la buscan a usted? ¡Los casos Ilegaron! Nada, la gente vive allá, en el municipio. Nuestras compañeras líderes escuchan a las víctimas, la gente empieza a contarnos... nosotras ni siquiera llegamos a documentar casos, llegamos por otra cosa, porque nuestro eje también son las políticas públicas a nivel municipal: plan de desarrollo, Consejo Municipal de Paz, porque tenemos que estar ahí, como nuestro activismo político diario... y pues nos encontramos con casos que después se convirtieron en emblemáticos

\footnotetext{
${ }^{14}$ Ángela relata que se trata de hombres que vivieron la desaparición de sus esposas e hijas; quienes vivieron la violencia sexual, o reclamaban la verdad frente a lo sucedido en el asesinato de su esposa o hija, ya que se sospechaba que antes del asesinato fueron víctimas de violencia sexual.

${ }^{15}$ Corregimiento del municipio de San Onofre, en el departamento de Sucre. La historia de este coregimiento está marcada por la presencia de grupos armados desde los años ochenta. En la segunda mitad de la década del noventa, la incursión de las Autodefensas Unidas de Colombia - AUC trajo consigo un repunte de la violencia que se extendió hasta mediados de los dos mil (Navas, 2017).
} 
para la Fiscalía y para el país ${ }^{16}$.

Por ejemplo, el caso de Riachuelo ${ }^{17}$ lo conocimos porque fuimos a hacer el Plan Local de Salud, había una discusión en el tema del acueducto veredal y nos encontramos con lo que pasaba en la comunidad por los efectos del paramilitarismo ${ }^{18}$. Yo creo que los casos llegaron a nosotras porque el destino los puso así...

Esto nos llevó a una experiencia de reconocimiento en el trabajo de víctimas y jurídico, el movimiento de mujeres poco a poco se fue dando cuenta de que las mismas mujeres querían estar en Justicia y Paz porque querían saber la verdad de lo que pasó con sus hijos, hijas o familiares; fue un dilema participar en Justicia y Paz, pero hoy considero que fue una gran oportunidad para hacer visible parte del horror de la guerra, de la resiliencia de las comunidades y de las mujeres, que son el soporte de la paz en el país.

\section{La participación en los diálogos de La Habana:}

"Las mujeres colombianas podemos aportar desde ya al proceso de diálogo y de construcción de paz, no pueden Ustedes esgrimir ningún argumento para negar la representación de las mujeres en todo el proceso. Es nuestro derecho, no solo reconocido por la ley, sino también ganado día a día con nuestro trabajo y compromiso...

(Cumbre Nacional de Mujeres y Paz, 2013) ${ }^{\mathbf{1 9}}$

Empezó el murmullo que iba a haber una negociación, que iba a pasar algo, pero nosotras como Alianza IMP como muy distantes. En algún momento se destapa el proceso y dijimos, otra vez nos cogieron aquí sin estar organizadas. Pero yo les dije: chicas, aquí tenemos que estar alertas, inosotras vamos a negociar, porque vamos a negociar!

Pasó el tiempo y en una reunión que nos convoca ONU Mujeres a varias organizaciones nos dicen que por qué no convocamos una asamblea de mujeres para hacernos visibles y juntarnos. Es la primera Cumbre Nacional de Mujeres y Paz $^{20}$ y ahí nos preguntamos: ¿cómo vamos las mujeres?, ¿qué está pasando con lo que se está acordando allá? Días antes de la Cumbre habían salido los

\footnotetext{
${ }^{16}$ Algunas de las experiencias de trabajo de la Alianza Iniciativa de Mujeres Colombianas por la Paz - IMP están sistematizadas en documentos disponibles en su sitio web: http://www.mujeresporlapaz. org/inf_publics.html

${ }^{17}$ Corregimiento del municipio de Charalá, en el departamento de Santander, fuertemente afectado por la violencia paramilitar entre los años 2000 y 2006 (Rodríguez, 2014).

18 Para un mayor contexto sobre lo ocurrido en Riachuelo, se recomienda revisar el artículo "La directora de escuela" (Gil, 2013).

19 Tomado del discurso de cierre de la Cumbre Nacional de Mujeres y Paz, pronunciado por Ángela Cerón Lasprilla el 25 de octubre de 2013.

${ }^{20}$ Se realizó por primera vez entre el 23 y el 25 de octubre del 2013, con el propósito de respaldar el proceso de paz que se llevaba a cabo entre el Gobierno de Juan Manuel Santos y las FARC-EP, exigir a las partes no levantarse de la mesa hasta llegar a un acuerdo e insistir en la presencia y la participación de las mujeres en todas las etapas de negociación, incluyendo la mesa de conversaciones en La Habana, Cuba (Muñoz y Ramírez, 2014).
} 
tres primeros acuerdos, el agrario, el de participación y el de drogas ilícitas, y las mujeres salíamos reducidas a un asunto de subsidios: para las mujeres lactantes, las mujeres de la tercera edad, las madres jóvenes cabeza de familia... todas nos preguntábamos ¿qué pasó? Así nos veía el Gobierno y así nos veían las FARC-EP, el patriarcado los unía...

En la Cumbre estábamos nueve organizaciones de mujeres, éramos como 600 mujeres, y me piden que pronuncie el discurso de cierre. Después de eso me di cuenta de que podía llegar a ser un referente en el movimiento de mujeres, que lograba buscar acuerdos. Es cuando agradezco todo el aprendizaje que recibí en el Departamento de la Mujer de la CUT, en el Partido Polo Democrático Alternativo, pero, sobre todo, lo que aprendí de las mujeres sindicalistas en la Escuela de Liderazgo, para ellas siempre será mi admiración y respeto.

Empezamos a consolidarnos como Cumbre y a tener más interlocución con las FARC-EP y el Gobierno. Surge la idea de hacer una primera reunión en La Habana para hablar de lo que les pasaba a las mujeres con los temas agrarios, de víctimas, de participación y drogas ilícitas. Esa fue como la entrada a la Subcomisión de Género ${ }^{21}$, ahí se conformó la Subcomisión; empezamos a tener una interlocución más directa, permanente, se dio la oportunidad de una audiencia especializada en delito de violencia sexual y yo llevé algunos casos. Todo eso dio la posibilidad de estar en el proceso de negociación.

La verdad nunca me sentí negociadora, pero me di cuenta de que nos reconocían como parte del escenario de la negociación. Algunos reconocen que estuvimos negociando temas de fondo... uno si estuvo ahí, pero yo creo que habría sido mejor si hubiéramos tenido más tiempo para incluir temas de los derechos de las mujeres. Pero para las mujeres fue importante estar ahí, nuestras voces también fueron importantes.

Ese escenario me gustó mucho, me sentía en misión imposible, ¡me sentía tan feliz!... siempre tuve la tensión de cuando usted llega y ve todo el escenario de lo que está pasando... me preguntaba: si esto es tan importante, ¿por qué aquí en Bogotá no logramos dimensionarlo? Pero cuando iba a las regiones, la gente era muy cercana a lo que estaba pasando. Fueron momentos de posicionar la voz de las mujeres, ese fue nuestro papel. El Gobierno poco a poco lo fue entendiendo, las FARC-EP creo que lo entendía un poco más porque en su estructura casi el $40 \%$ eran mujeres, ya eran mujeres poderosas y reconocidas en su liderazgo, pero no eran muy expertas en temas técnicos de incluir el tema de los derechos de las mujeres en las políticas públicas.

\footnotetext{
${ }^{21}$ La Subcomisión de Género hizo parte de la Mesa de Negociación entre el Gobierno Nacional y las FARC-EP en la Habana, Cuba. Se constituyó como fruto de la presión de los movimientos de mujeres y se instaló el 7 de septiembre de 2014. Constituye un hito, en tanto fue la primera vez, y es hasta ahora la única, en que un proceso de paz en el mundo contaba con una instancia de ese tipo, dirigida a abordar específicamente los temas relacionados con las mujeres en el conflicto armado (Suescún y Fajardo, 2017).
} 


\section{Los inicios de los diálogos con el Ejército de Liberación Nacional - ELN}

Alterno al proceso de fin del conflicto con la FARC-EP, el Gobierno de Santos adelantaba un proceso de diálogo y negociación con el ELN. Una vez se firmó en el Teatro Colón el Acuerdo Final22, nos dijimos: ahora nos toca apostarle con mayor fuerza a lograr un acuerdo con el ELN ${ }^{23}$. Sentía que trataban al ELN como el hermano menor de las guerrillas: menos presencia en el territorio, menos ejército... pero nosotras que tenemos presencia en las regiones sabemos que no es así y que es un actor importante en la guerra de Colombia. En el pasado habíamos ido como Alianza IMP a la cárcel de Itagüí a los procesos de Casa de Paz en la época de Uribe ${ }^{24}$, ahí habíamos tenido un acercamiento con el ELN. Así que empezamos a ir a Quito, Ecuador, para hablar de la experiencia de la Subcomisión de Género en el proceso con las FARC-EP y a trabajar algunos talleres en temas de género con el ELN, hasta que cerraron el proceso ${ }^{25}$. Con ellos desde el inicio se estaba trabajando en la importancia de los derechos de las mujeres; esa era la experiencia que ya traíamos.

\section{Sobre la Terapia Ocupacional}

Soy consciente que la experiencia del movimiento sindical me ha favorecido, esa escuela fue importante. De la universidad rescato el tema de los proyectos, siempre lo he dicho; la profesora Nora Stella Díaz nos dio una clase de elaboración de proyectos, a esa clase yo le he sacado todos los réditos del mundo. ¡No se imagina cada vez que me siento a hacer un proyecto cómo la recuerdo! Es la clase que más recuerdo.

En la práctica veía a la profesora Martha Torres haciendo sus proyectos con el CIAL ${ }^{26}$. Ella nos los dejaba leer y nos decía: aquí les toca intervenir, aquí tienen

\footnotetext{
${ }^{22}$ Acuerdo Final para la Terminación del Conflicto y la Construcción de una Paz Estable y Duradera, firmado en el Teatro Colón, de Bogotá, el 2 de octubre de 2016.

${ }^{23}$ El Ejécito de Liberación Nacional - ELN es una guerrilla colombiana fundada entre 1964 y 1965 por personas provenientes de sectores urbanos y universitarios, seguidoras de los ideales de la revolución socialista en América Latina (Vélez, 2001).

${ }^{24}$ De acuerdo con Castaño,"Casa de Paz fue un espacio propuesto el 8 de septiembre de 2005 por la Comisión de Garantes de la Sociedad Civil, como un lugar para la interlocución entre esta guerrilla [ELN] y diversos sectores de la sociedad civil (...), sectores institucionales y países amigos" (2012, p.207). Esto como parte de los diálogos exploratorios de paz entre el Gobierno de Álvaro Uribe Velez (2002 - 2010) y dicha guerrilla, que se llevaron a cabo entre los años 2005 y 2007.

${ }^{25}$ El proceso de negociación entre el Gobierno del entonces presidente Juan Manuel Santos y el Ejército de Liberación Nacional - ELN empezó oficialmente su fase exploratoria en junio de 2014 y su fase pública en marzo de 2016. La sede de los diálogos fue Quito, Ecuador. El 18 de enero de 2019 el presidente Ivan Duque rompe los diálogos con esta guerrilla después del atentadodel día anterior contra la Escuela de Policía General Santander en Bogotá, que dejó al menos 21 muertos y 68 heridos (Fundación Ideas para la Paz - FIP, 2019).

${ }^{26}$ Centro Integral de Adaptación Laboral - CIAL, dependencia del programa de Terapia Ocupacional de la Universidad Nacional de Colombia a través del cual se desarrollaron varios proyectos relacionados con los procesos de acompañamiento y asesoría a trabajadores que perdieron sus empleos como consecuencia del proceso de reestructuración del Estado en los años noventa, bajo la dirección de la profesora Martha Torres de Tovar.
} 
que interactuar. Recuerdo que alguna vez nos llevó al Ministerio del Trabajo y la vi interviniendo con una solvencia académica y política sobre los efectos del neoliberalismo en los trabajadores, que me dije: espero algún día llegar a ser como ella. Siempre he tenido como referente a la profesora Martha... ella siempre nos hablaba de la política, del Banco Mundial, de lo que estaba pasando; quizás uno ahí no lograba tener la relación de lo que eso significaba, con el tiempo lo va entendiendo... Me acuerdo que cuando se hizo el acuerdo entre la CUT y la Universidad debíamos presentar un proyecto, ella colocaba un contexto de Colombia, de lo que estaba pasando, cifras de desplazamiento, del conflicto.

Yo creo que el análisis de la coyuntura política es importante; eso no debe quedar solo en manos de los politólogos, eso debe ser también parte de nuestros argumentos... porque es que nosotras las terapeutas ocupacionales trabajamos fenómenos sociales y la relación ocupación-ser humano. Ahora recuerdo cuando llenábamos los formatos de la Fiscalía en la documentación de los casos, me tomaba mucho tiempo saber qué hacían en su vida diaria y qué había pasado el día que les tocó salir desplazadas o se presentó la masacre, o lo que perdieron en razón del conflicto armado... nunca encontraba espacio en el formato para decir que perdió la licuadora, la nevera o la máquina de coser; eso no era importante, no se consideraba como un bien... pero para mí era importante, porque era el medio de trabajo para muchas mujeres. Finalmente se entendió y ahora dentro de los daños se contabiliza cuando trabajamos el tema de las indemnizaciones.

Había otra materia que trataba el tema del plan de vida, eso me ha servido mucho con las víctimas. Algún día tendré que hacer un estudio de lo que las mujeres hicieron con la reparación administrativa, que fue un dinero que ellas recibieron por los daños que la guerra les causó. Me ha servido para trabajar con ellas sus proyectos productivos, no sé si son exitosos, pero la mayoría vive de ese pequeño proyecto que montaron con su indemnización.

Considero que es muy importante el papel del terapeuta ocupacional en los $E_{T C R^{27}}$. Porque es que al excombatiente le toca llegar a pagar la luz, el agua, y eso se convierte en un problema, y nos va a traer miles de inconvenientes si no somos conscientes de ello. Si no hay alguien que los oriente en lo que significan sus derechos y deberes, por ejemplo, recibir un salario; nuestro papel ahí es fundamental. Como también creo que ha sido con el tema de las víctimas de minas antipersona, es importante estar ahí. El análisis ocupacional que incluya la ética del cuidado será fundamental para los nuevos trabajadores y trabajadoras de la paz.

Como terapeutas ocupacionales debemos mirarnos un poco más hacia nuestra propia identidad, es importante saber la razón de..., si yo no sé cuál es mi objetivo, a dónde voy a llegar, en qué condiciones y cómo lo voy a hacer, pues mi

\footnotetext{
${ }^{27}$ Espacios Territoriales de Capacitación y Reincorporación - ETCR, creados a través del Acuerdo de Paz entre el Gobierno Nacional y las Fuerzas Armadas Revolucionarias de Colombia - FARC-EP para la reincorporación a la vida civil de excombatientes desmovilizados de esa guerrilla.
} 
accionar se va a quedar en lo que me enseñaron, sin la posibilidad de proyectar nada más en otras cosas que puedo crear. Quizás hay muchas posibilidades de crear tantas cosas, pero no lo hacemos porque creemos que eso no es. Yo siempre justifiqué mi accionar profesional por el trabajo con las mujeres y no como terapeuta ocupacional; aunque tenía ambos cartones, uno invisibilizaba al otro. En algunos escenarios no decía que era terapeuta ocupacional, pero de un tiempo para acá dije, lo voy a decir: soy terapeuta ocupacional.

\section{Referencias}

Centro Nacional de Memoria Histórica (2018). Justicia. Balance de la contribución del CNMH al esclarecimiento histórico. CNMH.

Castaño, O.M. (2012). Conflicto sin final, espejismo de la paz. Diálogos exploratorios en el Gobierno de Álvaro Uribe con el ELN (2005-2007). Estudios Políticos, 40, 201-220. https://revistas. udea.edu.co/index.php/estudiospoliticos/article/view/13211/11856

Cumbre Nacional de Mujeres y Paz (2013, 25 de octubre). Pronunciamiento de las mujeres participantes de la Cumbre Nacional de Mujeres y Paz, celebrada en la ciudad de Bogotá, entre el 23 y 25 de octubre de 2013. https://www.rutapacifica.org.co/ proyectos/cumbre-de-mujeres/166-pronunciamiento-de-las-mujeres-participantes-de-la-cumbre-nacional-de-mujeres-y-paz-celebrada-en-la-ciudad-de-bogota-entre-el-23-y-25-de-octubre-de-2013

Fundación Ideas para la Paz [FIP] (2019). EI proceso de paz con el ELN. Paso a paso de las conversaciones con este grupo guerrillero, antes y después de anunciar la agenda de negociación el 30 de marzo del 2016. http://www.ideaspaz.org/ especiales/eln/
Gil, L. (2013, 29 de octubre). La directora de la escuela. EI Tiempo. https://www. eltiempo.com/archivo/documento/CMS13149460

La Silla Vacía (2017, 24 de marzo). Luis González León. https://lasillavacia.com/quienesquien/perfilquien/luis-gonzalez-leon

Martínez, J. J. (2015). Impacto de las reformas económicas neoliberales en Colombia desde 1990. In Vestigium Ire, 8(1), 7891. http://revistas.ustatunja.edu.co/index. php/ivestigium/article/view/1003

Misión de Apoyo al Proceso de Paz en Colombia de la Organización de los Estados Americanos [OEA-MAPP] (2019). Tomo I. Informes del Secretario General para apoyar el proceso de paz en Colombia MAPP/OEA 2004-2007. MAPP/OEA. https://www.mapp-oea.org/wp-content/ uploads/2019/06/TOMO-I.pdf

Misión de Apoyo al Proceso de Paz en Colombia de la Organización de los Estados Americanos [OEA-MAPP] (s.f.). Acerca de la MAPP/OEA. Consultado el 10 de mayo de 2020. https://www.mapp-oea. org/mappoea/acerca-de-la-mappoea/ 
Muñoz, M. y Ramírez, C. (2014). Cumbre Nacional de Mujeres y Paz. Bogotá, octubre 23 al 25 de 2013. Sistematización. ONU Mujeres en Colombia.

Navas, N. (2017). Plan integral de reparación colectiva de Libertad (Sucre), expectativas y realidades de las víctimas (tesis de maestría, Pontificia Universidad Javeriana). Repositorio Javeriana. https://repository.javeriana.edu.co/hand$\underline{\text { le/10554/21868 }}$

Nieto, O. (2015, 25 de agosto). Un grupo de diez mujeres, representantes de ONG, se reúne con la Subcomisión de Género para compartir sus propuestas sobre víctimas de violencia sexual [fotografía]. Oficina del Alto Comisionado para la Paz, Presidencia de la República (2018), Biblioteca del Proceso de Paz con las FARC-EP. Tomo VII: Los mecanismos e instancias de participación de la mesa de conversaciones y la construcción de paz desde los territorios (p. 370).

ONU Mujeres (s.f.). Consejo de Seguridad. Consultado el 11 de mayo de 2020. https://www.unwomen.org/es/how-wework/intergovernmental-support/major-resolutions/security-council
Ríos, J. y Fuentes, E. (2014). La necesaria (y desatendida) dimensión social del Estado colombiano en la consecución de la paz. Revista Electrónica Iberoamericana, 8(1), 42-63. https://www.recp.es/files/ view/pdf/congress-papers/11-0/990/

Rodríguez, L. (2014). Interpretaciones, expectativas y percepciones de las mujeres víctimas de Charalá (trabajo de grado de pregrado, Universidad Santo Tomás). Repositorio USTA. https://repository.usta. edu.co/bitstream/handle/11634/2746/ Rodriguezlaura2014.pdf? sequence $=1$

Suescún, J. y Fajardo, J. (2017). Vivencias, aportes y reconocimiento: las mujeres en el proceso de paz en La Habana. Humanas Colombia - CIASE.

Vacas, F. (2014). Los acuerdos entre el Gobierno de Colombia y las autodefensas/ paramilitares: proceso negociador, contenido e implementación, y derechos de las víctimas. Revista Electrónica Iberoamericana, $8(1)$, 8-41.

Vélez, M.A. (2001). FARC - ELN: evolución y expansión territorial. DesarroIlo y Sociedad, 47, 151-225. https:// doi.org/10.13043/dys.47.4 